\title{
Metabolic and Electrolyte profile in Birth Asphyxia
}

\section{Kumar Singh A. ${ }^{1 *}$, Sharma B. ${ }^{2}$, Mehta A. ${ }^{3}$, Chand Gandhi K. ${ }^{4}$, Chandra Tiwari H. ${ }^{5}$ DOI: https://doi.org/10.17511/ijpr.2020.i07.03}

\footnotetext{
1* Abhishek Kumar Singh, Assistant Professor, Department of Pediatrics, BRD Medical College, Gorakhpur, Uttar Pradesh, India.

2 Bhoopendra Sharma, Professor, Department of Pediatrics, BRD Medical College, Gorakhpur, Uttar Pradesh, India.

3 Anita Mehta, Professor and Head, Department of Pediatrics, BRD Medical College, Gorakhpur, Uttar Pradesh, India.

${ }^{4}$ Karm Chand Gandhi, Senior Resident, Department of Pediatrics, BRD Medical College, Gorakhpur, Uttar Pradesh, India.

$\mathbf{5}$ Harish Chandra Tiwari, Assistant Professor, Department of Community Medicine, BRD Medical College, Gorakhpur, Uttar Pradesh, India.
}

Introduction: The definition of birth asphyxia is given by the ACOG, AAP includes the existence of 3 factors: Metabolic or mixed acidemia $(\mathrm{pH}<7)$ which is determined by umbilical cord arterial blood samples. The major causes of neonatal seizures are Hypoxic-ischemic encephalopathy (HIE), which represents about $50 \%$ of the causes of neonatal seizures. Metabolic abnormalities, infection, intracranial hemorrhage, developmental anomalies, and other like inborn errors of metabolism are other causes of neonatal seizures. Material and Methods: A cross-sectional study. This is a hospital-based prospective study conducted at Nehru Hospital, BRD Medical College, Gorakhpur (UP) in the Neonatal Intensive Care Unit of the pediatric department. This study was conducted from July 2018 to July 2019. Result: Prevalence of Hypocalcemia was 7.6\%, Prevalence of hypernatremia was $1.3 \%$, Out of 315 patients $32(10.2 \%)$ patients expired and $283(89.8 \%)$ was successfully discharged. Conclusion: No association between Hypocalcemia and Hypomagnesemia Prevalence of hyponatremia was $6.3 \%$ and no association between hyponatremia and Hypomagnesemia. The prevalence of hypernatremia was $1.3 \%$ and there was no association between hypernatremia and Hypomagnesemia.

Keywords: Birth asphyxia, Hypocalcemia, Hypernatremia

\section{Corresponding Author}

Abhishek Kumar Singh, Assistant Professor, Department of Pediatrics, BRD Medical College, Gorakhpur, Uttar Pradesh, India.

Email: abhisheksingh.brd.gkp@gmail.com
How to Cite this Article

To Browse

Singh AK, Sharma B, Mehta A, Gandhi KC, Tiwari HC. Metabolic and Electrolyte profile in Birth Asphyxia. Pediatric Rev Int J Pediatr Res. 2020;7(7):331-336. Available From

https://pediatrics.medresearch.in/index.php/ijpr/arti cle/view/624

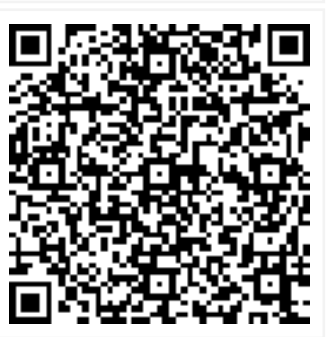

Manuscript Received 2020-09-07

Conflict of Interest No
Review Round 1 2020-09-19

Funding

$\mathrm{Nil}$

$\begin{gathered}\text { Review Round } 2 \\ 2020-10-02\end{gathered}$
Ethical Approval
Yes

Review Round 2

Yes
Review Round 3

Plagiarism X-checker 9\%
Accepted 2020-10-29

() 2020 by Abhishek Kumar Singh, Bhoopendra Sharma, Anita Mehta, Karm Chand Gandhi, Harish Chandra Tiwari and Published by Siddharth Health Research and Social Welfare Society. This is an Open Access article licensed under a Creative Commons Attribution 4.0 International License https://creativecommons.org/licenses/by/4.0/ unported [CC BY 4.0].
Note 


\section{Introduction}

Birth asphyxia is a serious clinical problem worldwide and contributes greatly to neonatal mortality and morbidity. The combination of the decrease in oxygen supply (hypoxia) and blood supply (ischemia) results in a cascade of biochemical changes inside the body, whose events lead to neuronal cell death and brain damage. Continuous asphyxia also leads to multiple organ systems dysfunction [1].

World Health Organization (WHO) defines Birth asphyxia as failure to initiate and sustain breathing in a newborn at birth [2].

Definition of birth asphyxia is given by the ACOG, AAP includes the existence of 3 factors: Metabolic or mixed acidemia $(\mathrm{pH}<7)$ which is determined by umbilical cord arterial blood samples; APGAR score of $<3$ for longer than $5 \mathrm{~min}$; neurological manifestations; and multisystem organ dysfunction [3]. The major causes of neonatal seizures are Hypoxic-ischemic encephalopathy (HIE), which represents about $50 \%$ of the causes of neonatal seizures. Metabolic abnormalities, infection, intracranial hemorrhage, developmental anomalies, and other like inborn errors of metabolism are other causes of neonatal seizures [4].

The causes of seizures in preterm neonates are different from those seen in term neonates, where the HIE is the most frequent cause in term neonates, followed by cerebral malformations and metabolic disturbances. In preterm neonates, intraventricular hemorrhage and infections are the most frequent causes [5]. Hypocalcemia is defined as total serum levels less $<7 \mathrm{mg} / \mathrm{dl}$, although the exact level at which seizure occurs is debatable.

Criteria for diagnosing biochemical abnormalities:

Hypoglycemia: blood sugar $<40 \mathrm{mg} / \mathrm{dl}$

Hypocalcemia: total serum calcium $<7 \mathrm{mg} / \mathrm{dl}$ and ionized serum calcium $<4.4 \mathrm{mg} / \mathrm{dl}$

Hypomagnesemia: serum magnesium $<1.5 \mathrm{mg} / \mathrm{dl}$

Hypermagnesemia: serem magnesium $>2.5 \mathrm{mg} / \mathrm{dl}$

Hypernatremia: serum sodium $>150 \mathrm{meq} / \mathrm{dl}$

Hyponatremia: serum sodium $<130 \mathrm{meq} / \mathrm{dl}$

Metabolic causes of neonatal seizures with a good prognosis are hypoglycemia, hypomagnesemia, hypocalcemia.
Some hypocalcemic seizure is accompanied by hypomagnesemia, but magnesium levels are rarely investigated in resource-restricted hospitals.

$87 \%$ of hypomagnesemia cases were associated with hypocalcemia implying the interrelation in pathophysiology. Among neonates with hypocalcemia, $20 \%$ had hypomagnesemia.

\section{Material and methods}

\section{Study structure}

Study Design: An observational study - Crosssectional study

Study Centre: This is a hospital-based prospective study conducted at Nehru Hospital, BRD Medical College, Gorakhpur (UP) in the Neonatal Intensive Care Unit of the pediatric department.

Duration of Study: This study was conducted from July 2018 to July 2019.

Ethical Approval: The study is approved by the institutional ethical committee (IEC) BRD medical college Gorakhpur.

Consent: Written informed consent was taken from parents in the local language.

\section{Case}

All cases of birth asphyxia are admitted every day in the NICU which includes between the age group of birth to 72 hours.

\section{Inclusion Criteria}

- All the term neonate of birth asphyxia who $\geq 37$ weeks of gestation.

\section{Exclusion Criteria}

- Preterm neonates

- Jitteriness in neonates

- Tetanic spasms in neonates

- The neonatal seizure was other than birth asphyxia.

- Newborn with congenital anomalies

Sample size:The sample size was determined using the following formula

$$
\begin{aligned}
& N=4 p q / L 2 \\
& N=4 \times 27 \times 73 /(5) 2=315 \\
& N=\text { required sample size }
\end{aligned}
$$


$P=$ Estimated prevalence of birth asphyxia $27 \%$

(Prevalence in India in the Year 2017) [42]

$Q=100-p$

$L=$ Margin error at 5\% (Standard value of 0.05 )

Methodology: A pre-structured proforma is used to record the information from the individual. After getting the consent from the parent's clinical data collected and inter in the proforma which includes age, sex, religion presenting complaints, type and duration of seizure, demographic details and examination, a maternal history risk factor for perinatal asphyxia age, weight, maternal education, preeclampsia, eclampsia, diabetes in mother, maternal infection, Multiple gestations, finding on admission are noted according to study proforma. All information is recorded in a pre-designed proforma.

Statistical Analysis: Collected data will be tabulated graphically displayed. Percentage, arithmetic mean and standard deviation to be calculated and data statistically analyzed using SPSS version 21 (statistical package for social sciences).

Interferential analysis for quantitative variables to be done using an independent ' $T$ ' test whereas analysis for qualitative data is done using the chisquare test. Statistical significance is set at ' $p$ ' $<0.05$. Data will be analyzed using standard methods. Consent will be taken from the attendants before enrolling the baby in the study.

\section{Result}

Table-1: Association of hypocalcemia and birth asphyxia.

\begin{tabular}{|l|l|l|}
\hline \multicolumn{1}{|c|}{ Ca level } & \multicolumn{1}{c|}{ N } & \multicolumn{1}{c|}{ Percent } \\
\hline Hypocalcemia & 24 & 7.6 \\
\hline Normal & 291 & 92.4 \\
\hline Total & 315 & 100.0 \\
\hline
\end{tabular}

In the present study, 24 (7.6\%) patient out of 315 was found to be hypocalcemia.

Table-2: Association of calcium level and magnesium level.

\begin{tabular}{|l|l|l|l|l|}
\hline \multicolumn{2}{|c|}{} & \multicolumn{2}{|c|}{ Mg level } & \multirow{2}{*}{ Total } \\
\cline { 3 - 5 } \multicolumn{2}{c|}{} & Hypomagnesemia & Normal & \\
\hline \multirow{3}{*}{ Ca level } & Hypocalcemia & 0 & 24 & 24 \\
\cline { 3 - 5 } & & $0 \%$ & $7.8 \%$ & $7.6 \%$ \\
\cline { 3 - 5 } & \multirow{4}{*}{ Normal } & 8 & 283 & 291 \\
\cline { 3 - 5 } & & $100.0 \%$ & $92.2 \%$ & $92.4 \%$ \\
\hline
\end{tabular}

Total

\begin{tabular}{|l|l|l|}
\hline 8 & 307 & 315 \\
\hline $100.0 \%$ & $100.0 \%$ & $100.0 \%$ \\
\hline
\end{tabular}

Applied $\div 2$ test for significance. $\div 2$ value $=0.677 ; p$ value $=0.411$; consider not significant.

In the present study, no patient had hypomagnesemia and hypocalcemia.

All patients of hypomagnesemia had normal calcium level, there was no association between hypomagnesemia and hypocalcemia.

Table-2: Association of Serum sodium and birth asphyxia.

\begin{tabular}{|l|l|l|}
\hline \multicolumn{1}{|c|}{ Na level } & \multicolumn{1}{c|}{ N } & \multicolumn{1}{c|}{ Percent } \\
\hline Hyponatremia & 20 & 6.3 \\
\hline Normal & 291 & 92.4 \\
\hline Hypernatremia & 4 & 1.3 \\
\hline Total & 315 & 100.0 \\
\hline
\end{tabular}

In the present study 20 out of 315 (6.3\%) had hyponatremia, 4 out of $315 \quad(1.3 \%)$ had hypernatremia and 291 out of 315 (92.4\%) had normal sodium level.

Table-3: Association of a high-risk factor in mother and birth asphyxia.

\begin{tabular}{|l|l|l|}
\hline \multicolumn{1}{|c|}{ H/o risk in mother } & \multicolumn{1}{|c|}{$\mathbf{N}$} & \multicolumn{1}{c|}{ Percent } \\
\hline Yes & 4 & 1.3 \\
\hline No & 311 & 98.7 \\
\hline Total & 315 & 100.0 \\
\hline
\end{tabular}

In the present study 4 out of 315 (1.3\%) patient's mothers had a significant antenatal history of risk factor.

Table-4: Association of meningitis and birth asphyxia

\begin{tabular}{|l|l|l|}
\hline \multicolumn{1}{|c|}{ Meningitis } & \multicolumn{1}{c|}{ N } & \multicolumn{1}{c|}{ Percent } \\
\hline Yes & 20 & 6.3 \\
\hline No & 295 & 93.7 \\
\hline Total & 315 & 100.0 \\
\hline
\end{tabular}

In the present study 20 out of 315 (6.3\%), patients had symptoms and lab investigations suggestive of meningitis.

Table-5: Outcome of the study.

\begin{tabular}{|l|l|l|}
\hline \multicolumn{1}{|c|}{ Outcome } & \multicolumn{1}{|c|}{ N } & \multicolumn{1}{c|}{ Percent } \\
\hline Expired & 32 & 10.2 \\
\hline Discharge & 283 & 89.8 \\
\hline Total & 315 & 100.0 \\
\hline
\end{tabular}

Out of 315 patient, 32 (10.2\%) patient expired and $283(89.8 \%)$ was successfully discharged. 
Table-6: Mean Serum calcium and Serum sodium.

\begin{tabular}{|l|l|l|l|l|l|l|l|}
\hline & Mean & SD & Median & Minimum & Maximum & Range & Count \\
\hline Serum Ca & 9.36 & 1.32 & 9.43 & 5.92 & 11.90 & 5.98 & 315 \\
\hline Serum Na & 139.00 & 4.46 & 139.30 & 124.60 & 161.50 & 36.90 & 315 \\
\hline
\end{tabular}

A mean of 2.07 with an SD of 0.39 was found for serum magnesium level

A mean of 9.36 with an SD of 1.32 was found for serum calcium level

A mean of 139 with an SD of 4.46 was found for serum sodium

\section{Discussion}

In the present study, 315 neonates with birth asphyxia were studied in 1 year. Both intramurally and extramurally delivered babies were included in this study. In a study by Asif Aziz Wani et al, a total of 100 consecutive neonates presenting with seizures from September 2013 to August 2014 were enrolled in the study. Clinical details of each seizure episode reported by the mother and subsequently observed by the resident doctors on duty were recorded.

It was found that around $54 \%$ of neonates had a biochemical abnormality alone or in association with other etiologies like hypoxic-ischemic encephalopathy (HIE), intracranial hemorrhage (ICH), meningitis, and sepsis. $31 \%$ of neonates had primary metabolic seizures. Hypocalcemia was the commonest biochemical abnormality in primary metabolic seizures and was present in $70 \%$ of neonates in this group. Hypoglycemia was the next common abnormality and was present in $41 \%$ of neonates within this group. 37 neonates (68.5\%) had biochemical abnormalities superimposed on other etiologies of neonatal seizures. Metabolic abnormalities were more commonly associated with intracranial hemorrhage $(53.8 \%)$ and birth asphyxia (50\%). Hypoglycemia $(22.7 \%)$ followed by hypocalcemia $(20.5 \%)$ were the commonest biochemical abnormalities in these patients. Hyponatremia was found in $20 \%(n=3)$ cases of meningitis and $15.4 \%(n=2)$ cases of ICH [6].

Arun Kumar A.R et al conducted a study on biochemical abnormalities in neonatal seizures in a tertiary care rural teaching hospital of south India in which out of 100 neonates with seizures, 69 were outborn (referred to the hospital from outside) and 31 were inborn. Seizures occurred more frequently among term infants (78\%).
One or more biochemical abnormalities were observed in $82 \%$ of neonates with seizures. Hypoglycemia $(44 / 82=53.65 \%)$ was the most common abnormality followed by hypocalcemia $(26 / 82=31.7 \%)$. He concluded that Hypoglycemia and hypocalcemia were the most common disturbances present not only as primary disorders but also associated with specific etiology. Early recognition and treatment are of utmost importance to decrease morbidity and mortality [7].

In a study of biochemical abnormalities in neonatal seizures with special reference to hyponatremia by Kamatham Madhusudhan et al 120 babies admitted with seizures in NICU were enrolled Biochemical abnormalities were found in 52 babies with the most common primary abnormality being hypoglycemia mostly encountered in preterm babies and the most common secondary abnormality being hyponatremia seen mostly in term babies.

Prompt identification of the biochemical abnormalities in neonatal seizures enables specific intervention by the treating doctor resulting in better neurological outcomes [8].

Imran Gattoo et al did a study on the Clinical and etiological profile of neonatal seizures he observed that Hypoxic ischemic encephalopathy was the commonest etiology of neonatal seizures. Intracranial hemorrhage followed by Hypoxic ischemic encephalopathy was the commonest seizure etiology in preterm neonates. Majority of Hypoxic-ischemic encephalopathy patients presented with seizures in the first $72 \mathrm{hrs}$. of life.

Focal clonic and subtle seizures were the commonest seizure types encountered. $31 \%$ of neonates had primary metabolic seizures. Hypocalcemia was the commonest biochemical abnormality in primary metabolic seizures and was present in $70 \%$ of neonates in this group. Hypoglycemia was the next commonest abnormality and was present in $41 \%$ of neonates within this group [9].

In a study done by Tanveer Nawab et al on the Clinical profile of neonatal seizures with special reference to biochemical abnormalities: Out of the 110 neonates studied, birth asphyxia was the commonest cause of neonatal seizures in $66(60 \%)$ cases, followed by neonatal sepsis and metabolic disorders. Primary metabolic abnormalities occurred in $13(11.8 \%)$ cases of neonatal seizures, most common being hypoglycemia9 $(69.3 \%)$ followed by hypocalcemia. 
Associated biochemical abnormalities were seen in $33(30 \%)$ cases with hyponatremia 13 (39.3\%) being most common followed by hypoglycemia. These were most often seen with Hypoxicischaemic- encephalopathy. He concluded that Biochemical abnormalities are common in neonatal seizures and often go unrecognized. These abnormalities may significantly contribute to seizure activity and hence a biochemical workup is necessary for all cases of neonatal seizures [10].

In the present study prevalence of hypocalcemia in birth asphyxia was $7.6 \%$, a study done by Suganthi $\checkmark$ et al [11] prevalence of hypocalcemia in birth asphyxia was $31.5 \%$, another study done by Jain $\mathrm{N}$ et al the prevalence of hypocalcemia was $28 \%$ [12] and a study done by Nawab T et al [13] had $23.7 \%$ cases of hypocalcemia in birth asphyxia. In all these three studies the prevalence of hypocalcemia was higher than the present study. None patients had hypocalcemia with hypomagnesemia was found while a study done by Suganthi $V$ et al [11] had $7.9 \%$ cases of hypocalcemia associated with hypomagnesemia and another study done by Saha $D$ et al had $3.33 \%$ cases had hypocalcemia with hypomagnesemia [14].

In the present study 20 out of 315 (6.3\%) had hyponatremia, 4 out of $315 \quad(1.3 \%)$ had hypernatremia while a previous study had $15 \%$ cases of hyponatremia and $5.8 \%$ of hypernatremia, and another study done by Kumar et al had $11.1 \%$ hyponatremia $[15,16]$. The value of the present study was lower than these two studies.

None of the patients had hyponatremia with hypomagnesemia; there was no association of hyponatremia and hypomagnesemia. In the present study 4 out of 315 (1.3\%) patient's mother had a significant antenatal history of high-risk factor, a study done by Aziz A et al [6] mothers with antenatal risk factor was $13 \%$ while a previous study done indicated $4 \%$ mothers had a history of high-risk factor which value was higher than the present study [15].

The mean value of serum calcium was $9.36 \mathrm{mg} / \mathrm{dl}$ in the present study while a study done by Saha $D$ et al mean serum calcium was $7.37 \pm 0.1 \mathrm{mg} / \mathrm{dl}$ which value was lower than the present study [14]. The mean value of serum sodium was $139 \mathrm{mEq} / \mathrm{L}$ found in the present study, a study was done by Basu $\mathrm{P}$ et al (2010) mean serum sodium was $122.1 \pm 6.0$ $\mathrm{mEq} / \mathrm{L}$ which value was lower than the present study [17].

\section{Conclusion}

From the study, it was concluded that the Prevalence of Hypocalcemia was $7.6 \%$ No association was found between Hypocalcemia and Hypomagnesemia Prevalence of hyponatremia was $6.3 \%$, and no association between hyponatremia and Hypomagnesemia. The prevalence of hypernatremia was $1.3 \%$ and there was no association between hypernatremia and Hypomagnesemia.

\section{What does the study add to the existing knowledge}

There have not been a lot of studies regarding the prevalence of metabolic and electrolyte profile with age gender, complications risk factor, and other electrolytes in birth asphyxia. In previous studies' role of understanding the metabolic and electrolyte profile of birth asphyxia, there should be more studies regarding metabolic and electrolyte profile in birth asphyxia.

\section{Author's contribution}

Dr. Abhishek Kumar Singh: Manuscript
preparation

Dr. Bhoopendra Sharma: Manuscript preparation

Dr. Anita Mehta: Data analysis

Dr. Karm Chand Gandhi: Concept, study design

Dr. Harish Chandra Tiwari: Manuscript review

\section{Reference}

01. Kumar A, Gupta A. Clinico-etiological and EEG profile of neonatal seizures. Indian J Pediatr. 2007;74(1)33-37.

doi: 10.1007/s12098-007-0023-0 [Crossref]

02. Sood A, Grover N, Sharma R. Biochemical abnormalities in neonatal seizures. Indian J Pediatr. 2003;70(3)221-224.

doi: $10.1007 /$ BF02725588 [Crossref]

03. Aslam HM, Saleem S, Afzal R, Iqbal U, Saleem $S M$, Shaikh MW, et al. Risk factors of birth asphyxia. Ital J Pediatr. 2014;40(1)94.

doi: 10.1186/s13052-014-0094-2 [Crossref] 
04. Jajoo D, Kumar A, Shankar R, Bhargana. Effect of birth asphyxia in serum Magnesium levels in neonate. Indian J Pediatr. 1995;62(4)455-459.

doi: $10.1007 /$ bf02755067 [Crossref]

05. Tekgul H, Gauvreau K, Soul J, Murphy L, Robertson R, Stewart J, Volpe J, Bourgeois B, du Plessis AJ. The current etiologic profile and neurodevelopmental outcome of seizures in term newborn infants. Pediatr. 2006;117(4)1270-1280.

doi: 10.1542/peds.2005-1178 [Crossref]

06. Wani AA, Ashraf S, Gatoo IA, Abdus S. Spectrum of biochemical abnormalities in neonatal seizures at a tertiary care hospital. Int J Develop Res. 2015;5(05)4311-4315/.

[Crossref]

07. Arunkumar AR, VR SR, Sumathi ME. Biochemical abnormalities in neonatal seizures in a tertiary care rural teaching hospital of South India. NJBMS. 2013;Jul;4.

[Crossref]

08. Madhusudhan K, Nadavapalli Suresh S, Babu TR, Rao JV, Kumar SB. Study of biochemical abnormalities in neonatal seizures with special reference to hyponatremia. Int $\mathrm{J}$ Contemp Pediatr. 2016;3(3)730-734.

doi: 10.18203/2349-3291.ijcp20162172 [Crossref]

09. Aziz A, Gattoo I, Aziz M, Rasool G. Clinical and etiological profile of neonatal seizures- a tertiary care hospital based study. Int J Res Med Sci. 2015;3(9)2198-2203.

doi: $10.18203 / 2320-6012 . i j r m s 20150601$ [Crossref]

10. Nawab T, Lakshmipathy NS. Clinical profile of neonatal seizures with special reference to biochemical abnormalities. Int $\mathrm{J}$ Contemp Pediatr. 2016;3(1)183-188.

doi: 10.18203/2349-3291.ijcp20160156 [Crossref]
11. Suganthi V, Vikneshwari K, Thivya G. Prevalence of hypomagnesemia in neonatal seizures in a tertiary care hospital in South India. Pediatr Rev- Int J Pediatrics Res. 2017;4(01)64-68. doi:10.17511/ijpr.2017.01.13 [Crossref]

12. Jain A, Agarwal R, Shankar MJ, Deorari A, Paul VK. Hypocalcemia in the newborn. Indin J Pediater. 2010;77( 10)1123-8.

doi: $\quad 10.1007 / \mathrm{s} 12098-010-0176-0 \quad$ [Crossref]

13. Nawab T, Lakshmipathy NS. Clinical profile of neonatal seizures with special reference to biochemical abnormalities. Int $\mathrm{J}$ Contemp Pediatr. 2016;3(1)183-188.

doi: 10.18203/2349-3291.ijcp20160156 [Crossref]

14. Saha D, Ali MA, Haque MA, Ahmed MS, Sutradhar PK, Latif $T$, et al. Association of hypoglycemia, hypocalcemia and hypomagnesemia in neonates with perinatal asphyxia. Mymensingh Med J. 2015;24(2)244250.

[Crossref]

15. Liamis G, Liberopoulos E, Alexandridis G, Elisaf M. Hypomagnesemia in a department of internal medicine. Magnesium Res. 2012;25(4)149-158. doi:10.1684/mrh.2012.0325 [Crossref]

16. Kumar AS, Gupta VE, Kachhawaha JS, Singla PN. Biochemical abnormalities in neonatal seizures. Indian Pediatr. 1995;32(4)424-428. [Crossref]

17. Basu P, Das H, Choudhuri N. Electrolyte status in birth asphyxia. Indian J Pediatr. $2010 ; 77(3) 259-262$.

doi: $\quad 10.1007 / \mathrm{s} 12098-010-0034-0 \quad$ [Crossref] 